ticularly when the preparation contains povidone. Unfortunately, our patient died from complications of unnecessary treatment given because the unfamiliar molar units used to report the phenobarbitone concentration were misinterpreted.

ADDENDUM-Since writing this report we have encountered a further case of serious but eventually reversible respiratory failure in a 46 year old man after aspiration of . Medicoal.

\section{Lyme disease with acute purulent meningitis}

\author{
S J Bourke, A G Baird, F J Bone, D R Baird, \\ R D Stevenson
}

Departments of

Respiratory Medicine and

Microbiology, Glasgow

Royal Infirmary, Glasgow

G31 2ES

S J Bourke, MRCPI, medical

registrar

D R Baird, MRCPATH, consultant microbiologist

R D Stevenson, FRCP,

consultant physician

Garrick Hospital, Stranraer

A G Baird, MRCGP, general practitioner

Dumfries and Galloway

Royal Infirmary, Dumfries

F J Bone, FRCPATH,

consultant microbiologist

Correspondence to: $\mathrm{Dr}$ Bourke.
Anonymous. Repeated oral activated charcoal in acute poisoning. Lancet 1987;i:1013-5.

2 Boldy DAR, Vale JA, Prescott LF. Treatment of phenobarbitone poisoning with repeated oral activated charcoal. Of Med 1986;61:997-1002

3 Pollack MM, Dunbar BS, Holbrook PR, Fields AI. Aspiration of activated charcoal and gastric contents. Ann Emerg Med 1981;10:528-9.

4 Dunbar BS, Pollack MM, Shavari MB. Cardiorespiratory changes after charcoal aspiration. Crit Care Med 1981;9:221.

5 Bergmann M, Flance IJ, Cruz PT, et al. Thesaurosis due to inhalation of hairspray. Report of 12 new cases, including three autopsies. $N$ Engl f Med 1962;266:750-5.

(Accepted 12 April 1988
Cases of Lyme disease with neurological manifestations have recently been reported in Britain ${ }^{12}$ and were well documented in the original reports of this disease from Connecticut. ${ }^{3}$ These neurological complications consist of a chronic lymphocytic meningitis often associated with cranial and peripheral neuritis. We report a case of Lyme disease with the undescribed complication of acute purulent meningitis.

\section{Case report}

A 69 year old man presented in May 1987 with a two month history of cough, haemoptysis, and pleuritic pain. He was under regular review for a transitional cell tumour of the bladder and had suffered a myocardial infarction six months earlier. A chest radiograph showed left upper lobe consolidation, but sputum cultures were negative. Appearances at bronchoscopy were normal, and transbronchial biopsy specimens showed an interstitial pneumonitis. Seven days after bronchoscopy he was readmitted to hospital with severe headache, photophobia, a fever of $38.5^{\circ} \mathrm{C}$, and severe neck stiffness. The peripheral white cell count was $16 \cdot 8 \times 10^{\circ} / 1(89 \%$ polymorphs $)$, and lumbar puncture yielded a purulent cerebrospinal fluid containing $2750 \times 10^{9}$ polymorphonuclear leucocytes per litre: protein concentration was raised at $1.6 \mathrm{~g} / \mathrm{l}$ and glucose reduced at $2 \cdot 1 \mathrm{mmol} / 1$ (blood glucose $8.2 \mathrm{mmol} / \mathrm{l}$ ). No organisms were seen on Gram, auramine, or Ziehl-Neelson staining. Latex coagglutination testing (Inverclyde Biologicals) of the cerebrospinal fluid was negative for pneumococcal capsular antigen, cultures of cerebrospinal fluid and blood remained sterile, and serological testing for viruses and Mycoplasma pneumoniae gave negative results.

He was given ampicillin and chloramphenicol for 14 days and antituberculous treatment (rifampicin, pyrazinamide, and isoniazid) for the first six days. A repeat lumbar puncture after seven days showed a fall in the polymorphonuclear count to $1020 \times 10^{9} / 1$. He developed a transient right facial palsy. Serial computed tomograms showed the development of an area of infarction in the right parietal region. A repeat chest radiograph showed resolution of the original consolidation. He made a partial recovery, but three months later, having returned to the care of his general practitioner, he remained disorientated, ataxic, and incontinent. Serological tests at this stage, arranged by his general practitioner, showed IgM antibodies to Borrelia burgdorferi at a titre of $1 / 512$ by indirect immunofluorescence. Retrospective examination of serum obtained at the time of his acute meningitis gave negative results, while serum taken five months later showed IgG but not IgM antibody at a titre of $1 / 256$, indicating a recent infection occurring around the time of the meningitis. He was negative for antinuclear antibodies, rheumatoid factor, and leptospira antibodies, and gave negative results to Treponema pallidum haemagglutination and Venereal Disease Research Laboratory tests. Six months after the initial presentation, when he had almost fully recovered, he developed a peripheral neuritis with a right foot drop, which improved after treatment with intravenous benzylpenicillin $12 \mathrm{MU}$ daily for two weeks. He recalled having had several tick bites while working on his farm but gave no history of a rash or arthropathy.

\section{Comment}

Our patient probably had Lyme disease complicated by acute pyogenic meningitis, though this has not been described before. He had the classic triad of neurological manifestations-meningitis, cranial neuritis, and late peripheral neuritis ${ }^{3}$ - and his serological findings were consistent with recent infection by $B$ burgdorferi. Other known causes of serological cross reactivity such as syphilis and leptospirosis were excluded ${ }^{4}$

We do not know why this patient responded to infection with $B$ burgdorferi with acute pyogenic meningitis, cerebral infarction suggestive of an associated vasculitis, and possibly pneumonitis. The virulence of the infecting organism may be relevant. North American and European strains of $B$ burgdorferi differ in their major proteins so we may expect to see differences between the disease in the United States and Britain. ${ }^{5}$ Erythema chronicum migrans and arthropathy are less common in European than in American cases. 5 At this stage in our knowledge of Lyme disease in Britain we would draw attention by this report to unusual presentations of the disease, which may reflect differences from the syndrome originally described in Connecticut.

We thank Dr D J M Wright, Charing Cross Hospital, London, for his help in performing and interpreting the serological tests.

1 Williams D, Rolles CJ, White JE. Lyme disease in a Hampshire child-medical curiosity or beginning of an epidemic? $\mathrm{Br}$ Med $\mathcal{F}$ 1986;292:1560-1

2 Bateman DE, White JE, Elrington G, Lawton NF. Three further cases of Lyme disease. Br Med J 1987;294:548-9.

3 Pachner AR, Steere AC. The triad of neurologic manifestations of Lyme disease: meningitis, cranial neuritis and radiculoneuritis. Neurology 1985; 35:47-53.

4 Muhleman MF, Wright DJM, Black C. Serology of Lyme disease. Lancet $1986 ; \mathrm{i}: 553-4$.

5 Barbour AG, Heiland RA, Nowe TR. Heterogeneity of major proteins in Lyme disease Borreliae: a molecular analysis of North American and European isolates. F Infect Dis 1985;152:478-84.

(Accepted 5 May 1988 